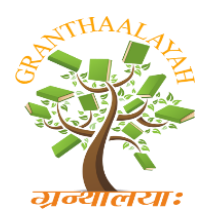

INTERNATIONAL JOURNAL OF RESEARCH -

GRANTHAALAYAH

A knowledge Repository

Social

\title{
A STUDY ON THE EFFECTIVENESS OF MULTIMEDIA IN TEACHING COMPUTER SCIENCE AMONG XI STANDARD STUDENTS IN KARUR DISTRICT
}

\author{
V.K. Subashini ${ }^{* 1}$ \\ ${ }^{* 1}$ Asst. Prof. in Computer Science, CMS College of Education, Ganapathy, Coimbatore, \\ Tamilnadu, INDIA
}

\begin{abstract}
This study attempted to find out the effect of using multimedia in teaching Computer Science among XI students. Sample of 62 students was selected for the study in Karur District. Two groups pretest and posttest experimental design was used. Data were analyzed. It is found that there is a significant means score difference between pretest and posttest among the selected higher secondary school novice students. It is proved that Multimedia supported teaching is one of the appropriate and effective methods for teaching Computer Science to higher secondary school students.
\end{abstract}

Keywords:

Students, multimedia, teaching, Computer Science.

Cite This Article: V.K. Subashini, "A STUDY ON THE EFFECTIVENESS OF MULTIMEDIA IN TEACHING COMPUTER SCIENCE AMONG XI STANDARD STUDENTS IN KARUR DISTRICT" International Journal of Research - Granthaalayah, Vol. 4, No. 5: SE (2016): 35-39.

\section{INTRODUCTION}

Education, in the present day context, is perhaps the single most important means for individuals to improve personal endowments, build capability levels, and overcome the constraints. Education is important not merely as means to other ends, but it is an attribute that is valued in itself, by most individuals. More importantly, it is a critical invasive instrument for bringing about social, economic and political inclusion and a durable integration of people, particularly those 'excluded', from the mainstream of any society. Computer Science today is about learning to understand the media we use every day. This idea for Computer Science has been around since at least the early 1960's but is most accessible through the well-known and highly regarded McLuhan statement "The medium is the message". Today, in the era of web 2.0, you are quite likely to think of social media, texting, and e-mail as common media you use frequently. In the strictest sense of the word, multimedia simply means "more than one medium". In other words, 
television programs, movies, even illustrated books are all examples of multimedia - they all use combinations of text, images, sounds, and movement.

\section{NEED FOR THE STUDY}

Computer is inevitable part in every walk of life today. The world has shrieked in to a global village and communication is revolutionized with the satellite communication. In this modern world of globalization and liberalization the teaching learning process is likely to enhance with the new vista of flooding universities of aboard.

The distance and open education offered at various levels would also plan to adopt new strategies of dissemination. Computer and Internet technologies are the order of the day and lessons preserved in computer based storage are not uncommon in the Libraries of Higher Education.

This new mode of delivery of lessons the burden of teacher and is appreciable way enhancing the participation of learners. The e-learning concepts of developed countries proved academically useful and hence the researcher made an attempt to present the Multimedia Package in a CD format developed for considering the learning theories and education maxims.

\section{OBJECTIVES OF THE STUDY}

The main objective of the study is to find out the effectiveness of Multimedia Teaching in Computer Science.

- To find out the significant difference in post-test score between male students who learnt through the conventional teaching method and male students who learnt through the Multimedia teaching method.

- To find out the significant difference in post-test score between female students who learnt through the conventional teaching method and female students who learnt through the Multimedia teaching method.

- To find out the significant difference in post-test score between male students and female students who learnt through the Multimedia teaching method.

- To find out the effectiveness of the Multimedia teaching method.

\section{HYPOTHESES OF THE STUDY}

- There is no significant difference between the post test score of Experimental Group and Control Group.

- There is no significant difference between the post test score of Boys and Girls in Experimental Group.

- There is no significant difference between the post test score of Experimental Group and Control Group for Boys.

- There is no significant difference between the post test score of Experimental Group and Control Group for Girls. 


\section{METHODOLOGY}

The investigator used experimental method to study about the effectiveness of using effectiveness of Multimedia Teaching in Computer Science of XI standard school students.

Sample: A total sample of 62 students was taken up for the present study. The investigator used to pre-test and post-test technique is used for the selection of sample. The stratification has been done on the basis of gender, pre-test and post-test.

Tool: The investigators developed a tool to measure the effectiveness of Multimedia Teaching in Computer Science of XI standard school students.

\section{DATA ANALYSIS}

The data was collected by the investigator using the tool developed for this purpose. All the data were collected by the investigator. Thematic analysis was undertaken with all qualitative data. For quantitative data analysis basic Descriptive statistics will be calculated. Pre and post-test scores will be compared using t-test. The difference in the per-test and post-test scores of experimental group is compared with the difference in the scores of pre and post test of control group.

\section{RESULT}

Table 1: Post test score of Experimental Group and Control Group

\begin{tabular}{|l|l|l|l|}
\hline \multicolumn{1}{|c|}{ Groups } & Mean & Standard Deviation & t - Value \\
\cline { 1 - 3 } Experiment group & 67.93 & 19.893 & \multirow{2}{*}{$2.299 * *$} \\
\hline Control group & 56.967 & 17.835 & \\
\hline
\end{tabular}

The significant of the mean difference is tested using $\mathrm{t}$ - test from the above table. It is clear that the calculated $t$ - value (2.299) greater than the table value (1.67) for degrees of freedom 60 at $1 \%$ level of significance.

Table 2: Post test score of Boys and Girls in Experimental Group

\begin{tabular}{|l|l|l|l|}
\hline Experimental group & Mean & Standard Deviation & t - Value \\
\hline Boys & 71.18 & 19.357 & $1.392 * *$ \\
\hline Girls & 60.22 & 20.11 & \\
\hline
\end{tabular}

The significant of the mean difference is tested using $\mathrm{t}$ - test from the above table. It is clear that the calculated $\mathrm{t}$ - value (1.392) is less than the table value (1.76) for degrees of freedom 14 at $1 \%$ level of significance.

Table 3: Post Score for Boys between Experiment Group and Control Group

\begin{tabular}{|l|l|l|l|}
\hline Boys & Mean & Standard Deviation & t - value \\
\hline Experiment group & 71.18 & 17.357 & $2.14 * *$ \\
\cline { 1 - 3 } Control group & 58.375 & 18.878 & \\
\hline
\end{tabular}


The significant of the mean difference is tested using $\mathrm{t}$ - test from the above table. It is clear that the calculated $\mathrm{t}$ - value (2.14) greater than the table value (1.69) for degrees of freedom 33 at $1 \%$ level of significance.

Table 4: Post Score for Girls between Experiment Group and Control Group

\begin{tabular}{|l|l|l|l|}
\hline Girls & Mean & Standard Deviation & t - value \\
\hline Experiment group & 60.22 & 20.11 & $0.591 * *$ \\
\cline { 1 - 3 } Control group & 55.46 & 17.179 & \\
\hline
\end{tabular}

The significant of the mean difference is tested using $\mathrm{t}$ - test from the above table. It is clear that the calculated $\mathrm{t}$ - value (0.591) greater than the table value (1.75) for degrees of freedom 15 at $1 \%$ level of significance.

\section{DISCUSSION AND FINDING}

The main objective of this study is to find out the knowledge of XI standard students. The data were analyzed by applying descriptive and inferential statistics. Out of the 4 hypothesis, 2 hypotheses were accepted and the remaining 2 were rejected.

- There is significant difference between the post test score of Experimental Group and Control Group students. This result is consistent with the result of Vivien E Rolfe and Douglas Gray (2011) and Amit Alok (2009)

- There is no significant difference between the post test score of Boys and Girls in Experimental Group. This result is consistent with the result of Pinal V. Patel (2009)

- There is significant difference between the post test score of Experimental Group and Control Group for Boys. . This result is consistent with the result of Pallavi Raje, S.V. Mahadevan(2009)

- There is significant difference between the post test score of Experimental Group and Control Group for Girls. This result shows that Experimental Group Girls are equal knowledge to Control Group Girls.

\section{CONCLUSION}

The investigator analyzed all the collected data and interpreted it descriptively and differentially. Finally the investigator has found that Multimedia packing plays effective role among XI students, hence their Multimedia presentation is to be improved in order to equip them to face the challenges in the future classrooms. Efforts are to be taking by the educational institutional to provide Multimedia facilities. Teachers are being potentially trained to make best use of the Multimedia in order to promote active learning. It is high time that Multimedia Technology be included in the teacher education curriculum. This will enable to meet the needs of the future challenges for students. This is study reflects the necessity of Multimedia Technology in Education.

\section{REFERENCES}

[1] Biranchi Narayan Dash (2003). TEACHER AND EDUCATIONAL IN THE EMERGING INDIAN SOCIETY (21-32), Hyderabad: Neelkamal Publication Pvt. LTD. 
[2] Dr.Bhalta.M.M. EDUCATIONAL IN EMERGING INDIAN SOCIETY Education in Emerging Indian Society, Ludhiana: Tandon Publication.

[3] David Haskin (2004). THE COMPLETE GUIDE TO MULTIMEDIA, USA: A Division of Macmillan Computer Publishing.

[4] Mary Fallenstein Hellman, W.R.James(2005). THE MULTIMEDIA, New York: A Division of International Thomson Publishing Inc.

[5] Golden, S. A. R. (2011). Problems and Prospectus of Distance Learning, Bharathidhasan University, 343- 344.

[6] Dr.Radhamohan (2005). Research methods in Education, Hyderabad: Neelkammal Publications PVT LTD.

[7] Henry E.Garrett (1969), Statistics Psychology and Education, Bombay: Vakils, Feffer and Simons Private LTD.

[8] John albert JemesV.kahn (2005). Research in Education - 9th -Perntice -Hall of India private limited - New Delhi.

[9] Mohd. Sharif khan (2004), Educational Research, New Delhi: Ashish Publishing House.

[10] Namda. V. K(2006). Education in Emerging Indian Society. Bangalore: Anmol Publications PVT. LTD.

[11] P.Saravanavel (2007). Research Methodology, Allahabad: KitabMahal, 22-A, sarojini Naidu Marg.

[12] Ramesh Verma (2002), Statistics Psychology and Education, New Delhi: Anmol Publications PVT LTD. 